\title{
STUDY OF THE IMPACT OF PETROLEUM HYDROCARBONS ON SEA ORGANISMS
}

\author{
Vitali Kurylenko' ${ }^{1}$ Oksana Izosimova ${ }^{1}$ \\ 1 Saint Petersburg State University, V.O. $10^{\text {th }}$ line 35, 199178, St. Petersburg, Russia, e-mail:v.kurilenko@spbu.ru
}

Received: 2015.11.11

Accepted: 2015.12 .09

Published: 2016.01.06

\begin{abstract}
According to many intenstigations, oil pollution cause difficult changes of structure and function of natural ecosystems, as well as violation of metabolic processes, production and destruction of organic matter, and consequently leads to a decrease in species diversity. Studies show that planktonic animals are quite sensitive to oil pollution of sea water, which accelerates their death in the concentration of $0.01 \mathrm{mg} \cdot \mathrm{dm}^{-3}$.
\end{abstract}

Keywords: hydrobionts, petroleum products, oil pollution.

\section{INTRODUCTION}

In recent years, under the conditions of intensive development of oil and gas fields on the continental shelf of the Russian Federation in connection with intensive development of oil fields in the Volga-Caspian region increased attention to the study of biological processes, as human pressure leads to a substantial reorganization of biological communities in the ponds. Currently, this kind of human activity is indulged, but in compliance with the conservation of the ecosystem ponds. In this regard, the study of planktonic organisms that are indicators of chronic water pollution, is very timely.

One of the biological problems that arise in connection with pollution of the seas and oceans, is the impact of petroleum hydrocarbons on sea organisms. On the one hand, it provides material for the calculation of the maximum allowable concentration of oil and oil products in sea water, with another opportunity to predict the consequences of sea pollution by hydrocarbons to the sea flora and fauna.

For a long time it was believed that, removing spilled oil from the surface of the ocean completely eliminates the risk of water pollution. However, studies have found that water-soluble fractions, which are the most toxic, remain in water. There is a need to determine possible toxicological stress on the ecosystem of the Caspian
Sea, to identify sea zones which are most sensitive and vulnerable to oil pollution . Experimental data and observations in natural conditions indicate the negative impact of oil and oil products on marine organisms from different taxonomic groups [Patin 1994].

Since the early 60 's, episodic, disjointed review the impact of organic pollutants on marine organisms of origin have become regularly focused on. Domestic and foreign scholars were convinced that in different experiments the reaction of the same species of organisms for the presence of toxic substances in the water may be opposite [Kryuchkov 2000]. This is due to the complexity of the pollutant. Oil, for example, is inherently a multicomponent substrate, which comprises as toxic compounds and useful biologically active substances.

Undoubted practical interest are eco-toxicological studies concerning the action of oil on sea organisms, because oil, due to its durability and long-term exposure, has the ability to accumulate and transfer through the food chain, as well as have a negative impact on the aquatic life of different trophic levels.

Oil pollution, according to numerous studies, causes complex changes in the structure and function of natural ecosystems, as well as violation of metabolic processes, production and destruction of organic matter, therefore, reduces the diversity of species composition, structure and 
monotonous to the loss of stability of ecosystems [Kurochkina 2008].

The last 10 years of observations showed that the highest values of oil pollution in the Volga river and Northern Caspian were recorded in 2004. In 2004, as part of the Volga runoff the highest content of petroleum hydrocarbons was recorded -53.7 thous. tons at sea.

In the Volga delta, the average annual value of petroleum hydrocarbons was 7 MPC fisheries in the North Caspian - 8.6 MPC. Minimum content of the petroleum hydrocarbons was noted in 2003 and it was about 3 MPC.

According to the materials of long-term monitoring in the North Caspian Sea, more than half of the cases $(54.1 \%)$ are in the concentration of petroleum hydrocarbons $(\mathrm{OU})$ in the amount of 0.5 to 3 MPC (Figure 1).

The impact of oil pollution can cause immediate death of animals in the places of most intense pollution, reduce their abundance to less contaminated areas. Under the influence of contamination occurs a selection of the most resistant individuals, acquired resistance to new pollution [Patin 1994].

Petroleum can have a different effect on animals, depending on their physiological state, the chemical composition of the oil, its concentration, temperature, water, etc. Thus, at a concentration of $0.001 \mathrm{mg} \cdot \mathrm{dm}^{-3}$ oil and petroleum products accelerate the death of plankton [4]. In zooplankton abundance mortality increases $2-56$ times. The number of copepods increased to $70 \%$ of the total population, the number of rotifers decreased more than 2-fold [Patin 1994]. Oil pollution can cause both inhibition and stimulation of phytoplankton community. The stimulatory effect of oil affects when activated heterotrophic processes of decomposition of organic matter of oil.

\section{RESULTS}

The results of experimental observations have shown that in terms of pollution only the most resistant species survive. The study of such species opens the prospect possibility of their use for purification of polluted water and sanitation of coastal waters. Most resistant to oil pollution were clam (Pitar rudis) and polychaetes (Nephthy hombergii), also resistant to oil pollution shrimp (Leander abspersus) compared with crab Pilumnus hirtelus [Kurochkina 2008]. Crab Pachygrapsus crassipes oil suppress reactions to food and mating, and lobsters purified fractions of oil (kerosene, in particular) are attracted. Acartia clausi marked difference in the sensitivity to oil pollution, depending on gender. Females were less susceptible than males. The number of females in the 5-day-experiment was several times higher than the number of males for the same source [Patin 1994]. Oil pollution is a violation of behavioral responses in crabs that are recovered after washing.

The results are our experimental studies and analysis show fairly high sensitivity dominants of Caspian zooplankton to petroleum products. The study of the Caspian Calanipeda aquadulci, Eurytemora affinis and crustaceans filter feeders in the experiments values LC50 (concentration of toxicant, causing the death of $50 \%$ of the animals) for oil exceeds the MPC in an aqueous medium in 2-20 times. When there are sub-lethal concentrations in the environment the activity of crus-

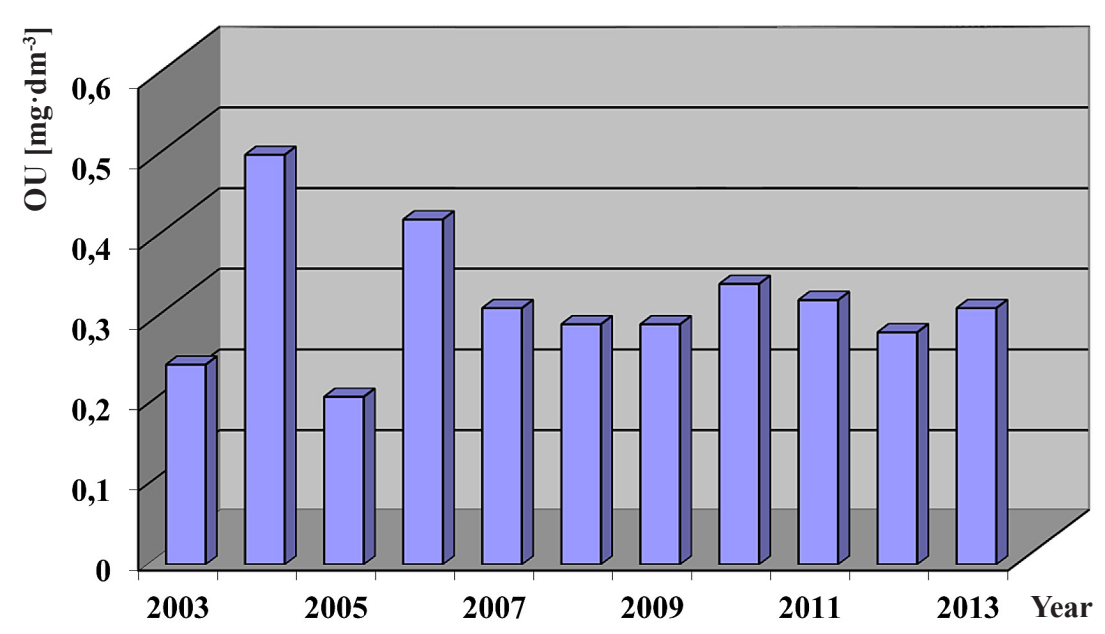

Figure 1. Average values of petroleum hydrocarbons (OU) in the North Caspian 2003-2013 
taceans is disrupted or reduced the rate of food consumption.

Under the action of emulsifiers of oil on the copepod of Centropages typicus and Acartia clausi, tserripedy nauplii, polychaete larvae, organisms studied to reduce the resistance to toxicants can be arranged in a number of larvae of polychaetes and copepods - nauplii. Analysis of the literature showed that the most resistant to petroleum products are the larvae of polychaetes, leading planktonic lifestyle.

When the effect of oil pollution on Acartia clause been pretty clear, the relationship between the duration of the life of organisms and the concentration of oil in seawater. Toxic effects observed at a concentration of $0.001 \mathrm{mg} \cdot \mathrm{dm}^{-3}$. At a concentration of $0.05 \mathrm{ml} \cdot \mathrm{dm}^{-3}$ organisms died on the fifth day, at $0.1 \mathrm{mg} \cdot \mathrm{dm}^{-3}$ - in the first day of the experiment. We have carried out experimental work on zooplankton sampled in the coastal area of the North Caspian Sea. Mineral oil was used as a diesel fuel at concentrations of $0.05,0.15$ and $3.0 \mathrm{mg} \cdot \mathrm{dm}^{-3}$.

Studies have found that the toxic effect of diesel fuel appears even at a concentration of 0.05 $\mathrm{mg} \cdot \mathrm{dm}^{-3}$ on day 3 , when the number of plankton decreased 3 times on average. On the $5^{\text {th }}$ day of observation further decline of zooplankton was noted. With increasing exposure, time grings their gradual extinction and on the $7^{\text {th }}$ day of exposure zooplankton survival was only $30 \%$, relative to the control. At a concentration of $3.0 \mathrm{mg} \cdot \mathrm{dm}^{-3}$, organisms die on the first day and by the end of the exposure $90 \%$ of the deaths of individuals was observed.

Toxic effect of diesel fuel can be traced to changes in species structure zoocenosis, expressed in decrease of the percentage of species. Thus, in a control experiment, zooplankton was represented by 20 species, dominated copepod nauplii, crustaceans Calanipeda aquadulci, Cyclops sp., Polyphemus pediculus, D. Longispina, B. Longirostris. In the test samples by the end of exposure the number of species was reduced to 3-5.

Fully killed nauplii significantly reduced their numbers crustaceans filter feeders. Most resistant to the action of the toxicant were Suslors sp., Br. calyciflorus, Br. plicatilis. The experimental work carried out on zooplankton Calanipeda aquadulci, Harpacticoida and Acartia clausi showed a negative effect of diesel fuel.

The data obtained from natural zoocenosis showed that the death of zooplankton occurs on day 3 with a concentration of $0.5 \mathrm{mg} \cdot \mathrm{dm}^{-3}$ and increases with time. The concentration of 10.0 $\mathrm{mg} \cdot \mathrm{dm}^{-3}$ has a devastating effect already at a two-night exposure, ie experiments with natural zoocenosis shown their high sensitivity to even small concentrations of petroleum products. The negative impact of their manifested in reducing the total number of species and changes in the structure. The most sensitive to the action of the toxicant were nauplii and fine filter feeders. In most cases, nauplii are more sensitive to oil and die much faster than adults. This finding is consistent with literature data on the increased sensitivity of early stages of ontogeny of aquatic organisms to toxic stress effects [Patin 1997].

On the basis of experimental work for petroleum products can make a number of organisms, is most sensitive to oil pollution. It may be noted the high sensitivity of Acartia clausi, A. Tonsa, Paracalanus parvus, Calanipeda aquadulci, Eurytemora (nauplii), Polyphemus pediculus, D. longispina.

\section{CONCLUSIONS}

Studies, as well as literature data suggest that the currently existing levels of pollution of the marine waters (excluding emergencies, areas adjacent to the subsea oil development, and some ports) are generally detrimental to the early developmental stages of aquatic organisms and do not lead to a rapid and mass extinction adult organism. Therefore, in most cases it is impossible to ascertain a direct link, for example, between the visible and the subsequent oil pollution him change in marine organisms. Appeared on the surface of the oil pretty quickly penetrates into the depths of the sea, emulsifying, dissipates accumulated in the bottom sediments, and the effects of such pollution can affect a reasonable period of time.

Under natural conditions, the effects of oil pollution of aquatic communities are exposed, and the defeat of a species of this community leads to a restructuring of ecological communities, thus greatly contributes to the susceptibility of different species of organisms to oil pollution.

The situation is aggravated by the fact that many of the areas are in a state of chronic oil pollution. If even further discharge of oil will stop someone else will take a long time before a self- 
cleaning process it will be destroyed and cease to cause adverse biological effect. Thus, the existing observations is enough to make a definite judgment about the adverse effects of falling into the sea of hydrocarbons on marine organisms.

The toxic effect of oil and petroleum products is manifested in a wide range of concentrations (from $10^{-2}$ to $10^{-5} \mathrm{mg} \cdot \mathrm{dm}^{-3}$ ), and affects all types of aquatic organisms and groups at all stages of their development.

Threshold effects and reactions begin to appear in a range of concentrations of oil in the water around $10^{-2}-10^{-1} \mathrm{mg} \cdot \mathrm{dm}^{-3}$ and relate mainly to the early stages of development of aquatic organisms. Analysis of long-term data shows that over the last 10 years the level of oil pollution of the Volga-Caspian is from 3.5 to 4.2 MPC.

Oil pollution, according to numerous studies, causes complex changes in the structure and function of natural ecosystems, as well as violation of metabolic processes, production and destruction of organic matter, and thus leads to a decrease in species diversity. Studies show that planktonic animals are very sensitive to oil pollution of sea water, what accelerates their death in the concentration of $0.01 \mathrm{ml} \cdot \mathrm{dm}^{-3}$.

\section{REFERENCES}

1. Kryuchkov V.I. 2000. Eksperimentalnye data on the effect of oil pollution on vegetation function sturgeon. Hooks Ekologiya, 1, 1040-1044.

2. Kurochkina T.F. 2008. Environmental safety during exploration in the North Caspian. Natural Nauki, 4, 235-237.

3. Kurotshkina T.F. 2008. Influence of hydrocarbons on the ecosystem of the lower Volga. In: T.F. Kurotshkina, O.S. Markov, E.V. Tleuleeva (Eds.) Proceedings of $2^{\text {nd }}$ International Conference "Fundamental and applied problems of modern chemistry" (15-17 April 2008), Astrakhan Izd. Dom., Astrakhan University, 204-208.

4. Patin S.A. 1994. Dobycha oil and gas offshore, ecological and fishery analysis. Ryb. Hoz., 5, 16-18.

5. Patin S.A. 1997. Ecological problems of oil and gas resources of the sea shelf. VNIRO, pp. 32. 